\title{
PENGELOMPOKAN DESA/KELURAHAN DI KOTA DENPASAR MENURUT INDIKATOR PENDIDIKAN
}

\author{
Ni Wayan Aris Aprilia A.P ${ }^{\S 1}$, I Gusti Ayu Made Srinadi ${ }^{2}$, Kartika Sari ${ }^{3}$ \\ ${ }^{1}$ Jurusan Matematika, Fakultas MIPA - UniversitasUdayana [Email:arisaprilia27@ gmail.com] \\ ${ }^{2}$ Jurusan Matematika, Fakultas MIPA - UniversitasUdayana [Email:srinadi@unud.ac.id] \\ ${ }^{3}$ Jurusan Matematika, Fakultas MIPA - UniversitasUdayana [Email:sari_kaartika@yahoo.co.id] \\ ${ }^{\S}$ Corresponding Author
}

\begin{abstract}
Cluster analysis is one of data analysis used to classify objects in clusters which has objects with the same characteristics, whereas the other cluster has different characteristics. One part of the method of analysis cluster is hierarchy method. In a hierarchical method there are methods of linkage in the form of incorporation. Generally, methods of linkage is divided into 5 methods: single linkage, complete linkage, average linkage, Ward and centroid. The purpose of this study was to determine the best method of linkage among the method of single linkage, complete linkage, average linkage, and Ward, using Euclidean and Pearson proximity distance. Base on the smallest value of CTM (Cluster Tightness Measure), the best method of linkage as a result of this research was average linkage in Pearson distance.
\end{abstract}

Keywords: Euclidean distance, Pearson distance, Linkage methods, CTM

\section{PENDAHULUAN}

Metode pautan merupakan bagian dari metode hirarki dalam analisis gerombol (cluster analysis), yaitu suatu proses penggabungan. Analisis gerombol adalah salah satu teknik analisis data yang digunakan untuk mengelompokkan obyek-obyek, sehingga dalam satu gerombol tergabung obyek dengan karakteristik yang sama, dan memiliki karakteristik yang berbeda dengan gerombol lain (Hair, et al [1]). Metode-metode yang merupakan metode pautan meliputi metode single linkage, complete linkage, average linkage, Ward dan centroid.

Pembentukan matriks jarak baru dalam metode pautan dengan metode single linkage menggunakan kriteria jarak minimum, sering disebut pendekatan tetangga terdekat (nearestneighbor). Jarak minimum antara ( $i j)$ dengan kelompok lain misalkan kelompok $w$ dituliskan sebagai:

$D_{(i j) w}=\min \left\{d_{i w}, d_{j w}\right\} \quad$ dengan $d_{i w}$ dan $d_{j w}$ secara berturut-turut adalah jarak dari gerombol $i$ ke gerombol $w$ dan dari gerombol $j$ ke gerombol $w, D_{(i j) w}$ merupakan jarak terdekat antara gerombol $i$ dan $w$ serta gerombol $j$ dan $w$. Misalkan dimiliki matriks jarak objek 1 sampai dengan objek 5 seperti matriks berikut.

$$
\mathrm{D}=d_{i j}=\begin{aligned}
& 1 \\
& 2 \\
& 3 \\
& 4 \\
& 5 \\
& 5
\end{aligned}\left[\begin{array}{llllll}
0 & & & & \\
9 & 0 & & \\
3 & 7 & 0 & \\
6 & 5 & 9 & 0 \\
1110 & 2 & 8 & 0
\end{array}\right]
$$

Objek dengan jarak terdekat digabung menjadi satu yaitu objek 3 dan 5 menjadi (35), selanjutnya dilakukan pembentukan matriks jarak dengan metode pautan single lingkage dengan perhitungan sebagai berikut:

$$
\begin{aligned}
& d_{(35) 1}=\min \left\{d_{31}, d_{51}\right\}=\min \{3,11\}=3 \\
& d_{(35) 2}=\min \left\{d_{32}, d_{51}\right\}=\min \{7,10\}=7 \\
& d_{(35) 4}=\min \left\{d_{34}, d_{54}\right\}=\min \{9,8\}=8
\end{aligned}
$$

Matriks jarak baru yang terbentuk adalah:

$$
d_{i j}=\begin{gathered}
(35) \\
1 \\
2 \\
4
\end{gathered}\left[\begin{array}{llll}
0 & 3 & 7 & 8 \\
3 & 0 & 9 & 6 \\
7 & 9 & 0 & 5 \\
8 & 6 & 5 & 0
\end{array}\right]
$$


Jarak terdekat adalah objek (35) disimbulkan objek $\left(3^{*}\right)$ dengan objek 1 , selanjutnya objek $\left(3^{*}\right)$ digabung dengan objek 1 membentuk $\left(3^{*} 1\right)$. Prosedur perhitungan matriks jarak baru identik dengan yang dilakukan sebelumnya, dengan perhitungan:

$$
\begin{aligned}
& d_{(3 * 1) 2}=\min \left\{d_{3 * 2}, d_{12}\right\}=\min \{7,9\}=7 \\
& d_{(3 * 1) 4}=\min \left\{d_{3 * 4}, d_{14}\right\}=\min \{8,6\}=6
\end{aligned}
$$

Matriks jarak baru menjadi:

$$
\begin{gathered}
\left(3^{*} 1\right) \\
d_{i j}= \\
\left(3^{*} 1\right) \\
2 \\
4
\end{gathered}\left[\begin{array}{lll}
0 & 7 & 6 \\
7 & 0 & 5 \\
6 & 5 & 0
\end{array}\right]
$$

Prosedur ini akan dilakukan sampai semua pasangan objek dengan jarak minimum diperoleh dan bergabung menjadi satu gerombol. Hasil perhitungan digambarkan dalam bentuk dendogram.

Pada metode complete linkage, pembentukan matriks jarak baru berdasarkan jarak maksimum antara dua objek atau gerombol. Average linkage menggunakan jarak rata-rata antara dua gerombol. Metode Ward ditentukan dari jumlah kuadrat jarak dari dua gerombol berdasarkan semua variabel. Jarak dalam metode centroid merupakan jarak antara dua gerombol yang didefinisikan sebagai jarak Euclidean antara vektor mean (Rencher [2]).

Pendidikan merupakan salah satu unsur penting dalam pembangunan. Untuk mengetahui karakteristik tingkat pendidikan desa/kelurahan di Kota Denpasar dilakukan pengelompokan berdasarkan data indikator pendidikan. Indikator-indikator pendidikan dalam penelitian ini meliputi banyak sekolah TK, SD, SMP, SMA/SMK, banyak siswa TK, SD, SMP, SMA/SMK, dan banyak guru TK, SD, SMP, SMA/SMK. Penelitian ini bertujuan untuk mengetahui metode pautan terbaik di antara metode single linkage, complete linkage, average linkage, dan Ward dalam mengelompokkan desa/kelurahan di Kota Denpasar menurut indikator pendidikan.

Kriteria yang digunakan dalam penentuan metode terbaik adalah Cluster Tightness Measure (CTM). CTM adalah ukuran perkiraan efektivitas dalam kelompok, rancangan ukuran antar kelompok, dan ukuran pemisahan dalam suatu kelompok. CTM diukur berdasarkan simpangan baku pada masing-masing kelompok seperti ditulis dalam persamaan berikut (Sutanto[3]):

$$
C T M=\frac{1}{r} \sum_{t=1}^{r}\left(\frac{1}{p} \sum_{m=1}^{p} \frac{s_{t m}}{S_{m}}\right)
$$

dengan

r : banyaknya kelompok

$\mathrm{p}$ : banyaknya variabel

$\mathrm{S}_{\mathrm{tm}}$ : simpangan baku pada kelompok ke-t untuk variabel ke-m

$\mathrm{S}_{\mathrm{m}}$ : simpangan baku variabel ke-m

Pemilihan metode pautan terbaik dilihat berdasarkan nilai CTM terkecil.

\section{METODE PENELITIAN}

Data yang digunakan dalam penelitian ini adalah data sekunder yang berasal dari publikasi Badan Pusat Statistik (BPS) yaitu data Dinas Pendidikan Pemuda dan Olahraga, yaitu data indikator pendidikan pada 43 desa/kelurahan di Kota Denpasar tahun 2013. Indikator pendidikan yang menjadi variabel penelitian sebanyak 12 variabel yaitu banyak sekolah TK, SD, SMP, SMA/SMK, banyak siswa TK,SD SMP,SMA/SMK, dan banyak guru TK, SD, SMP, SMA/SMK.

Langkah-langkah analisis data sebagai berikut:

1. Melakukan standarisasi data.

2. Melakukan pngecekan korelasi.

3. Jika ada korelasi yang signifikan antara variabel dilakukan analisis komponen utama untuk membentuk komponen-komponen yang saling bebas, selanjutnya skor komponen yang diperoleh dipandang sebagai variabel untuk analisis lebih lanjut, jika tidak ada korelasi yang signifikan maka dilanjutkan ke langkah 4.

4. Mengukur kesamaan obyek (similarity) menggunakan jarak Euclidean [2] dengan rumus:

$$
d_{i j}^{E}=\sqrt{\sum_{k=1}^{p}\left(x_{k i}-x_{k j}\right)^{2}}
$$


dan jarak Pearson yang menggunakan rumus (Sutanto [3]):

$$
d_{i j}^{P}=\sqrt{\sum_{k=1}^{p} \frac{\left(x_{k i}-x_{k j}\right)^{2}}{\operatorname{var}\left(x_{k}\right)}}
$$

5. Menjelaskan setiap anggota kelompok yang terbentuk pada masing-masing metode pautan yaitu single linkage (Johnson \& Wichern [4]) dengan rumus:

$D_{(i j) w}=\min \left\{d_{i w}, d_{j w}\right\}$

complete linkage [4] dengan rumus:

$D_{(i j) w}=\max \left\{d_{i w}, d_{j w}\right\}$

average linkage [4] dengan rumus:

$D_{(i j) w}=\frac{\sum_{n} \sum_{k} d_{n k}}{N_{(i j)} N_{w}}$

serta metode ward (Rencher [2])

menggunakan rumus:

$$
S S E_{i j}=\sum_{k=1}^{n_{i j}}\left(\mathbf{y}_{\mathbf{k}}-\overline{\boldsymbol{y}}_{\boldsymbol{i} \mathbf{j}}\right)^{\prime}\left(\mathbf{y}_{\mathbf{k}}-\overline{\boldsymbol{y}}_{\boldsymbol{i} \mathbf{j}}\right)
$$

6. Melakukan pemilihan metode terbaik berdasarkan nilai CTM terkecil.

7. Interpretasi hasil.

\section{HASIL DAN PEMBAHASAN}

\subsection{Deskripsi Data}

Desa/kelurahan di Kota Denpasar ada sebanyak 43 dengan beberapa indikator pendidikan saling berkorelasi secara signifikan. Terlebih dahulu dilakukan analisis komponen utama untuk memperoleh skor komponen yang saling bebas. Skor komponen-skor komponen yang selanjutnya dianalisis dengan analisis gerombol untuk mengelompokkan desa/kelurahan di Kota Denpasar.

\subsection{Penentuan Gerombol dengan Metode Single Linkage}

Pengelompokan dilakukan berdasarkan kedua jarak kedekatan (jarak Euclidean dan Pearson). Pada jarak Euclidean, plot diagram pencar memperlihatkan bahwa banyak gerombol yang terbentuk adalah 7, seperti pada Gambar 1.

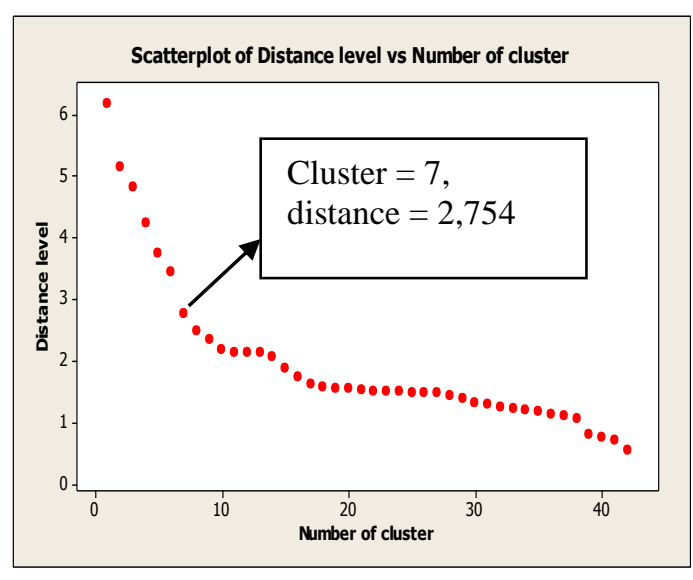

Gambar 1. Diagram Pencar Metode Single Linkage pada Jarak Euclidean

Pada jarak Pearson, banyak gerombol yang terbentuk adalah 3 seperti pada Gambar 2.

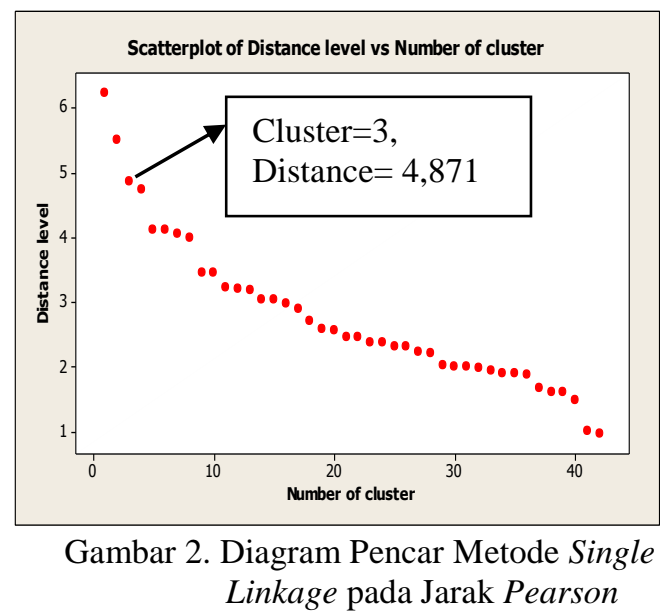

\subsection{Penentuan Banyak Gerombol dengan Metode Complete Linkage}

Proses penggerombolan dan pembentukan matriks jarak baru menggunakan persamaan (4). Sedangkan plot diagram pencar digunakan untuk menentukan banyaknya gerombol seperti pada Gambar 3 dan Gambar 4.

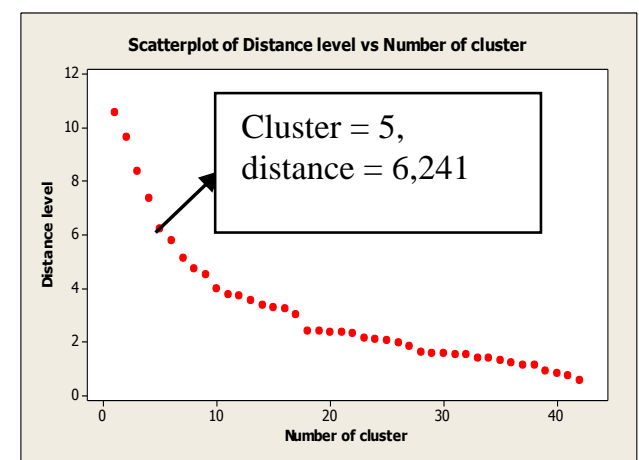

Gambar 3. Plot Diagram Pencar Metode Complete Linkage pada Jarak Euclidean 


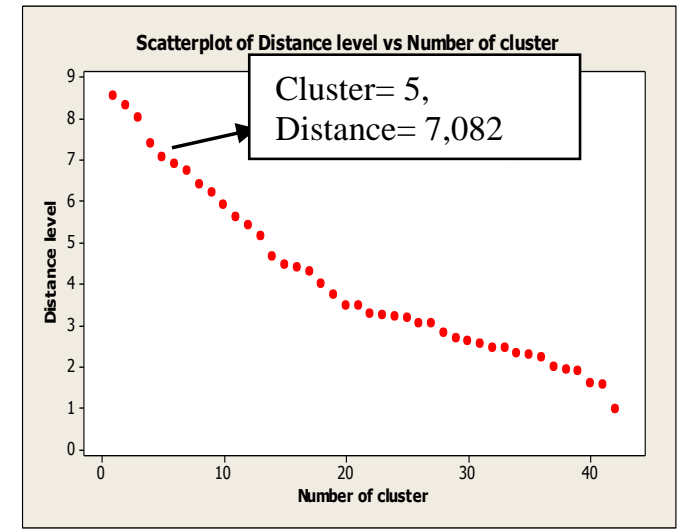

Gambar 4. Plot Diagram Pencar Metode Complete Linkage pada Jarak Pearson

Terbentuk 5 gerombol dengan metode Complete Linkage pada jarak Euclidean dan jarak Pearson.

\subsection{Penentuan Banyak Gerombol dengan Metode Average Linkage}

Banyaknya gerombol yang terbentuk pada metode average linkage dilihat berdasarkan plot diagram pencar antara jarak Euclidean dan Pearson, dilihat pada Gambar 5 dan Gambar 6.

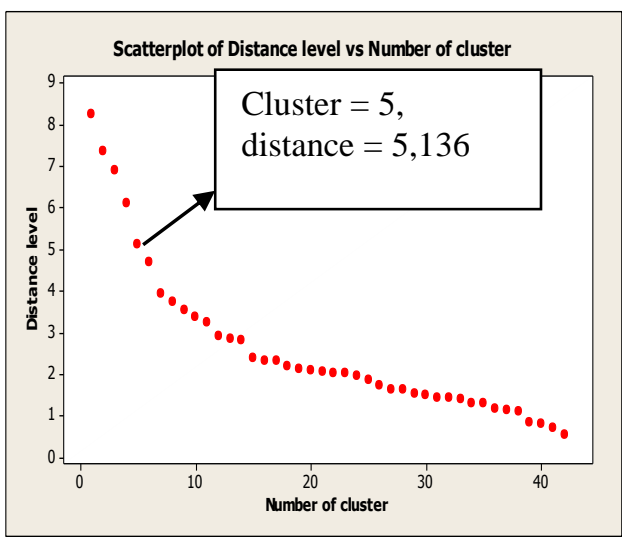

Gambar 5. Plot Diagram Metode Average Linkage pada Jarak Euclidean

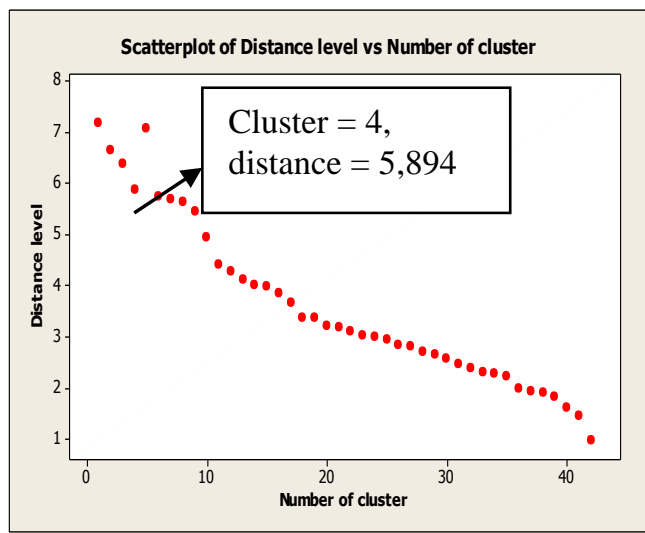

Gambar 6. Plot Diagram Pencar Metode Average Linkage pada Jarak Pearson
Terbentuk 5 gerombol pada jarak Euclidean dan 4 gerombol pada jaran Pearson dengan metode Average Linkage.

\subsection{Penentuan Banyak Gerombol dengan Metode Ward}

Pada metode Ward, dengan menggunakan plot diagram pencar untuk jarak Euclidean banyak gerombol yang terbentuk dapat dilihat pada Gambar 7. Gambar 8 menunjukkan banyak gerombol yang terbentuk pada jarak Pearson.

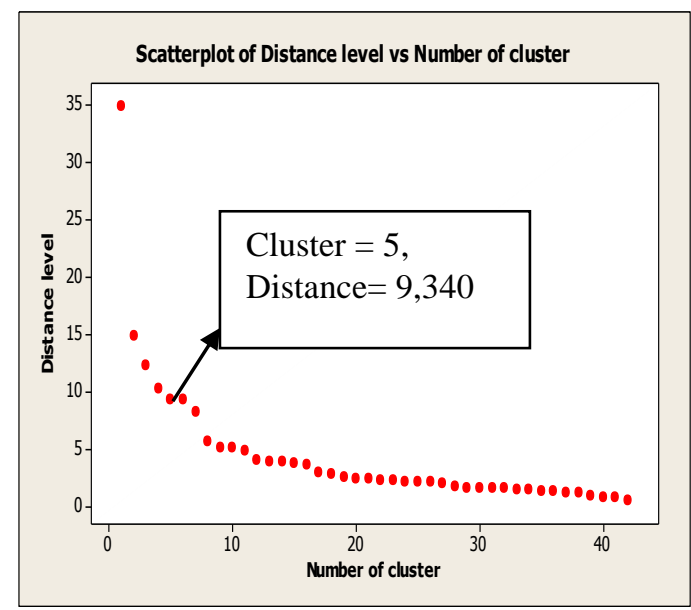

Gambar 7. Plot Diagram Pencar Metode Ward pada Jarak Euclidean

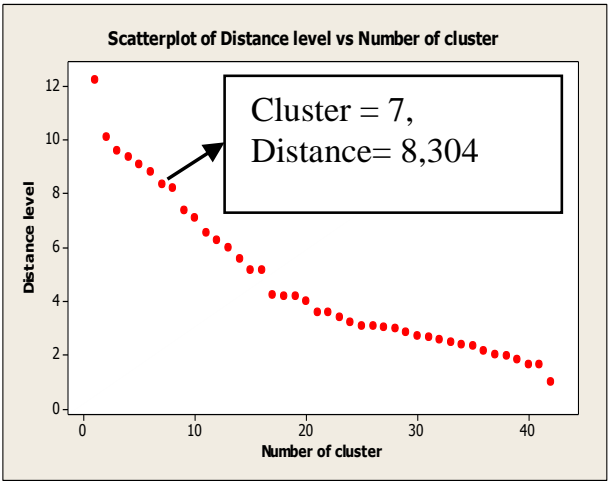

Gambar 8. Plot Diagram Pencar Metode Ward pada Jarak Pearson

Dengan metode Ward, pada jarak Euclidean terbentuk 5 gerombol dan 7 gerombol terbentuk pada jarak Pearson.

\subsection{Penentuan Metode Terbaik}

Pemilihan metode terbaik dengan menggunakan kriteria Cluster Tightness Measure (CTM) terkecil. Hasil perhitungan CTM pada masing-masing metode pautan dapat dilihat pada Tabel 1 
Tabel 1. Metode Terbaik Menggunakan CTM

\begin{tabular}{|l|l|l|}
\hline \multirow{2}{*}{ Metode } & \multicolumn{2}{|l|}{ Nilai CTM dari Jarak } \\
\cline { 2 - 3 } & Euclidean & Pearson \\
\hline $\begin{array}{l}\text { Single } \\
\text { Linkage }\end{array}$ & 0,0909 & 0,0196 \\
\hline $\begin{array}{l}\text { Complete } \\
\text { Linkage }\end{array}$ & 0,0409 & 0,0411 \\
\hline $\begin{array}{l}\text { Average } \\
\text { Linkage }\end{array}$ & 0,0399 & 0,0183 \\
\hline Ward & 0,0663 & 0,0535 \\
\hline
\end{tabular}

Berdasarkan Tabel 1 dapat dilihat bahwa metode pautan terbaik dalam mengelompokkan desa/kelurahan di kota Denpasar berdasarkan indikator pendidikan metode average linkage pada jarak kedekatan Pearson. Dendogram hasil pengelompokan metode average linkage pada jarak Pearson dapat dilihat pada Gambar 9.

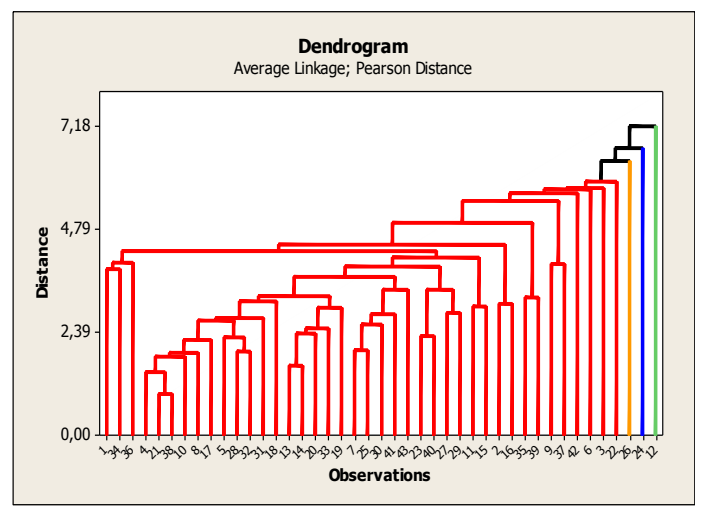

Gambar 9. Dendogram Hasil Pengelompokan Average Linkage pada Jarak Pearson

Dengan jarak kedekatan Pearson, metode pautan Average Lingkage, 43 desa/kelurahan di kota Denpasar dikelompokkan dalam 4 kelompok. Satu kelompok beranggotakan 40 desa/kelurahan dan 3 desa/kelurahan lainnya masing-masing merupakan kelompok tersendiri, diuraikan pada Tabel 2.

Hasil pengelompokan ini menunjukkan bahwa Desa Sumerta Klod, Desa Dangin Puri Kauh, dan Desa Dangin Puri Kangen memiliki indikator pendidikan dengan karakteristik yang berbeda dari ke-40 desa/kelurahan lainnya di kota Denpasar yang tergabung dalam kelompok 1. Pada kelompok 1, variabel yang dominan menentukan karakteristik pendidikan pada kelompok ini adalah variabel $X_{1}$ (banyak sekolah TK).
Tabel 2. Pengelompokan Desa/Kelurahan dengan Metode Average Linkage pada Jarak Pearson

\begin{tabular}{|c|c|c|}
\hline Kel & \multicolumn{2}{|c|}{ Anggota Kelompok } \\
\hline I & $\begin{array}{ll}\text { 1. } & \text { Desa Pemogan } \\
\text { 2. } & \text { Kel. Pedungan } \\
\text { 3. } & \text { Kel.Sesetan } \\
\text { 4. } & \text { Desa Serangan } \\
\text { 5. } & \text { Desa Sidakarya } \\
\text { 6. } & \text { Kelurahan Panjer } \\
\text { 7. } & \text { Kelurahan Renon } \\
\text { 8. } & \text { Desa Sanur Kauh } \\
\text { 9. } & \text { Kelurahan Sanur } \\
\text { 10. } & \text { Desa Sanur Kaja } \\
\text { 11. Desa.Dangin Puri } \\
\text { Klod } \\
\text { 12. Desa Dauh Puri } \\
\text { Kaja } \\
\text { 13. Desa Dangin Puri } \\
\text { Kaja } \\
\text { 14. Kel. Tonja } \\
\text { 15. Kel. Peguyangan } \\
\text { 16. Kelurahan Ubung } \\
\text { 17. Desa Ubung Kaja } \\
\text { 18. Desa Peguyangan } \\
\text { Kaja } \\
\text { 19. Desa Peguyangan } \\
\text { Kangin } \\
\text { 20. Desa } \\
\text { Padangsambian } \\
\text { Klod } \\
\text { 21. Desa } \\
\text { Pemecutann } \\
\text { Klod } \\
\text { 22. Kelurahan } \\
\text { Kesiman } \\
\text { 23. Desa Kesiman } \\
\text { Petilan } \\
\text { 24. Desa Kesiman } \\
\text { Kertalangu } \\
\text { Dana }\end{array}$ & \begin{tabular}{|rl} 
25. & Kelurahan \\
26. & Desa Sumerta \\
& Kaja \\
27. & Desa Sumerta \\
& Kauh \\
28. & Kelurahan Dangin \\
& Puri \\
29. & Kelurahan Penatih \\
30. & Desa Penatih \\
Dangin Puri \\
31. \\
Desa Pemecutan \\
Kaja \\
32. \\
Desa Dauh Puri \\
Kauh \\
33. \\
Desa Dauh Puri \\
Klod \\
34. Kelurahan Dauh \\
Puri \\
35. Desa Dauh Puri \\
Kangin \\
36. Kelurahan \\
Pemecutan \\
37. Desa Tegal Arum \\
38. Desa Tegal Kerta \\
39. Kelurahan \\
Padangsambian \\
40. Desa \\
Padangsambian \\
Kaja
\end{tabular} \\
\hline II & Desa sumerta KIod & \\
\hline III & Desa Dangin Puri K & \\
\hline IV & Desa Dangin Puri K & \\
\hline
\end{tabular}

\section{KESIMPULAN}

Berdasarkan kriteria nilai CTM terkecil diperoleh bahwa metode pautan terbaik yang digunakan dalam pengelompokan desa/kelurahan di kota Denpasar berdasarkan indikator pendidikan adalah metode average linkage. 


\section{DAFTAR PUSTAKA}

[1] Hair, Joseph.F. et.al. 1995. Multivariate Data Analysis with Readings Fourth Edition. United State of America: Prentice-Hall International, Inc.

[2] Rencher, A.C. 2002. Methods of Multivariate Analysis Second Edition. New York: John Wiley and Son, Inc.

[3] Sutanto, H.T. 2009. Cluster Analysis. http://core.ac.uk/download/pdf/1106 4649.pdf. Diakses 14 April 2015

[4] Johnson, R.A. \& Dean.W.Wichern. 2007. Applied Multivariate Statistical Analysis Sixth Edition. United State of America: Pearson Education, Inc. 